\title{
LOS ENTES LOCALES COMPLEJOS Y OTRAS FORMAS DE COLABORACION EN EL ORDENAMIENTO LOCAL ITALIANO
}

\author{
POR \\ Tomas Quintana Lopez \\ Profesor titular de Derecho Administrativo en la Universidad de León
}

\begin{abstract}
SUMARIO: I. INTRODUCCION. - II. LAS FORMULAS DE COLABORACION INTERMUNICIPAL EN EL Derecho vigente: 1. Los consorcios en el régimen local italiano. 2. Las Comunidades de montaña. 3. La colaboración entre entes locales en el marco de la reforma sanitaria. 4. Otras fórmulas de composición de intereses interterritoriales. 5. A modo de recapitulación. - III. LOS ENTES LOCALES INTERMEDIOS EN LOS INTENTOS DE REFORMA DEL Regimen local: 1. El llamado Proyecto de Pavía y los sucesivos de finales de los años 70. 2. Proyecto de la IX Legislatura, presentado el 16 de abril de 1985. 3. La colaboración intermunicipal en los textos propuestos en la actual (X) Legislatura.
\end{abstract}

\section{INTRODUCCION}

Italia, al igual que otros Estados europeos -entre los que hay que incluir algunos de la Italia preunificada- asume el modelo napoleónico de uniformidad municipal. Decididamente, la Ley número 2248, de 20 de marzo de 1865, de unificación administrativa, opta por la uniformidad del modelo local para todo el país, la cual aún hoy se mantiene a través de la generalización de las entidades más significativas: municipios y provincias. El revolucionario principio de igualdad, tan escrupulosamente respetado - al menos en las formas-sugirió la constitución de un municipio en cada comunidad territorial por lo que en Italia, en el presente decenio se cuentan más de 8.000 municipios (1); multiplicidad de entes municipales, uniforme regulación -obviamente enfrentada con la diversidad real entre ellos-, obsolescente normativa (contenida fundamentalmente en el t. u., 4, de febrero de 1915 , número 148; t. u., 3 de marzo de 1934, número 383 y en el Reglamento de 12 de febrero de 1911, número 297) y, sobre todo, las dificultades financieras por las que atraviesan, son algunos de los males que con reiteración se diagnostican al régimen local italiano. Pues bien, frente a este cúmulo de aspectos negativos, en

(1) Según datos referidos al 31 de diciembre de 1982, en Italia existen 8.086 municipios, de los cuales 4.718 no alcanzan los 3.000 habitantes, y de ellos 768 son inferiores a 500 habitantes. Vid. Luciano Vandelli, en colaboración con Sergio Bartole y Franco Mastragostino: Le autonomie territoriali; ordinamiento delle Regioni e degli enti locali. II Mulino, Bologna, 19.88, p. 201. 
Italia como en otros países del entorno europeo occidental se ha levantado un debate en busca de soluciones para los problemas que afectan a este sector del ordenamiento; debate que en relación al abultado número de municipios y su acusada ineficacia, reconduce las soluciones o bien a la consolidación de niveles superiores de cooperación, coordinación y asociación municipal (concepción funcional), o bien, a una radical transformación estructural de los municipios, fundamentalmente a través de la fusión (concepción estructural) (2). Los defensores de esta primera vía (3) ponen su confianza en los entes intermedios y otras formas de colaboración de carácter subprovincial y supramunicipal; son a estas fórmulas cooperativas en general, a su regulación, funcionamiento y evolución en el ordenamiento italiano a las que dedicaremos las páginas que siguen.

\section{LAS FORMULAS DE COLABORACION INTERMUNICIPAL EN EL DERECHO VIGENTE}

\section{Los consorcios en el régimen local italiano}

El grueso de la regulación sobre los consorcios, es decir, agrupaciones de entes locales, está recogida en el t. u. Ley de 3 de marzo de 1934; concretamente son los artículos 156 y ss. los que se ocupan de esta institución (4). Las posibilidades que ofrece este texto son variadas; en efecto, permite la constitución de consorcios para la realización de obras o la gestión de servicios entre municipios, y de éstos con la provincia, entre provincias, y de éstas con uno o más municipios; incluso prevé la posible participación en ambos tipos de consorcios de otros entes públicos, siempre que éstos estén autorizados por las normas a que se hallen sujetos.

Si reparamos en el origen, además de los que deben su constitución a la Ley, ésta también puede venir dispuesta coactiva-

(2) Cfr. L. VANDELLI: «I modelli associativi nei progetti di riforma del governo locale», Quaderni Regionali, FORMEZ, núm. 39, p. 171. También, F. MATTEUCCI y T. GıORGETI: «l consorzi in Emilia Romagna: un analisi empirica», Regione e goberno locale, núm. 4, 1988, pp. 8 y 9.

(3) Partidario de una radical reducción del número de municipios, como presupuesto de reforma del régimen local italiano, se manifestaba $M$. S. GIANNINI; contrariamente, el influyente grupo redactor del Proyecto de Pavía, en 1976, entendía que la fusión de municipios debía ser la meta a la que conducirian las formas de colaboración intermunicipal ofrecidas por la Ley de régimen local que se redactara. Vid. L. VANDELLI: / modelli associativi..., cit., pp. 174 y 175.

(4) Existen, no obstante, normas específicas aplicables para regular consorcios relativos a obras o servicios determinados (construcción y mantenimiento de carreteras, cementerios, mataderos...), vid. L. VANDELLI y ötros: Le autonomie territoriali..., cit., p. 278. 
mente por autoridad administrativa (5), lo que ocurrirá en los casos en que la Ley haya previsto la realización de la obra o el cumplimiento del servicio obligatoriamente a cargo de entes consorciados. Naturalmente, el consorcio puede nacer también del acuerdo voluntario de los entes que pretenden consorciarse, en cuyo caso, la constitución debe ser aprobada en última instancia por la autoridad administrativa nacional o regional, según los casos (6).

Este mismo órgano administrativo, tanto para los consorcios obligatorios como los facultativos, aprueba el Estatuto, instrumento que ha de indicar el fin, la duración, los órganos que lo representan, sus atribuciones, la participación de los entes consorciados en los gastos, y cualquier norma que precise su administración. Como órganos necesarios, el artículo $159 \mathrm{t}$. u.. hace referencia a una asamblea consorcial, compuesta por representantes de los entes consorciados, según lo previsto en el propio Estatuto del Consorcio y de acuerdo con la contribución que cada ente realice a los gastos generales (art. 161), un consejo consorcial o directivo, un presidente, además de un secretario nombrado por la asamblea; en cualquier caso, el Estatuto puede prever la constitución de algunos órganos.

La participación de los entes consorciados en los gastos que genere el consorcio son repartidos entre ellos de común acuerdo, quedando reflejados en un Estatuto los criterios determinantes del

(5) El art. 157 del t. u. Ley 1934, dispone en su segundo apartado: «La constitución coactiva del consorcio es decidida por Decreto del Prefecto, si los entes pertenecen a la misma circunscripción provincial; por el Ministerio del Interior, si pertenecen a circunscripciones provinciales diversas, oidos los Consejos municipales y las Juntas provinciales administrativas interesadas, $y$, cuando del consorcio forme parte la provincia, también el Consejo provincials. Sin embargo, no está claro que estas competencias sigan reservadas a órganos estatales; cfr. las opiniones de L. VANDELLI: Le autonomie territoriale..., cit., p. 278, para quien la constitución coactiva de consorcios aún se mantienen reservada al Estado, con la de M. AimonetTo y $F$. GAFfodio: Testo unico della legge comunale e provinciale, MAGGIOLI, Rimini, 1987, pp. 207 y 208 , opinión esta última de la que parece desprenderse que esa responsabilidad ha pasado a las regiones para la constitución de consorcios referidos a competencias de éstas.

Por su parte, el artículo 170 del mismo texto dispone: «... varias provincias, por Decreto del Ministro del Interior, emitido de acuerdo con los Ministros competentes, oídos los respectivos Consejos provinciales y la Junta provincial administrativa, pueden ser agrupadas en consorcio para proveer a determinados servicios y obras de carácter obligatorio.

En los mismos casos y con las mismas formas, oídos también los Consejos municipales interesados, se puede proveer a la constitución coactiva de consorcios entre provincias y uno o más municipios». Tratándose de municipios y provincias pertenecientes a una misma región se plantea el mismo debate a cerca de la competencia para consorciar coactivamente; no parece dudoso, sin embargo, que perteneciendo aquéllos a Regiones distintas la competencia quede retenida por el Estado, que ejerce a través del Ministro del Interior.

(6) Aunque el artículo $156 \mathrm{t}$. u. Ley 1934 otorga, en unos casos al Prefecto y en otros al Ministro del Interior, y el artículo 169, también del t. u. otorga esta competencia al Ministro del Interior, lo cierto es que la aprobación última que precisan los consorcios facultativos por parte de la autoridad administrativa distinta de los entes consorciados, corresponde a la Región o al Estado en función de que las materias a gestionar por el consorcio estén o no transferidas a la Región (Corte Constituzionale, sentencia número 130, 26 de mayo de 1976). 
reparto. El dato básico en que ha de apoyarse éste es el interés de cada uno de los entes, y a falta de otros criterios válidos para definir ese interés, el artículo 160 ofrece como dato a considerar la población y las rentas catastral e industrial.

Los consorcios, tanto facultativos como obligatorios, según establece el artículo $162 \mathrm{t}$. U., son entes morales, a los que la jurisprudencia reiteradamente ha reconocido personalidad jurídica pública y diversa de la de los entes que los componen. En cuanto a su funcionamiento, deliberaciones, finanzas y contabilidad, vigilancia y tutela gubernativa se aplican a los consorcios las normas dispuestas para la provincia, en aquellos casos en que ésta forme parte; en otro caso, las relativas al municipio consorciado que cuente con el mayor número de habitantes, o bien las aplicables al municipio capital de provincia cuando forme parte del consorcio. Algún detenimiento merece el análisis de la vigilancia y tutela gubernativa; tratándose de consorcios formados entre municipios o en los que participara la provincia inicialmente (art. 165 t. u.) el control gubernativo estaba encomendado en su totalidad al Prefecto y a la Junta provincial administrativa; con posterioridad, por Ley de 10 de febrero de 1953, número 62 (7), se añade al t. u., el artículo 165 bis, que remite el control de los consorcios que ahora tenemos en cuenta a las normas que esta Ley prevé para el control de los municipios y provincias; en concreto, el artículo 97 bis, también agregado por la citada Ley del 53, en relación con sus artículos 55 y 56, dispone que los poderes de control atribuidos al Prefecto y a la Junta provincial administrativa se transfiere para las provincias $y$, con algunos matices, para los municipios, a los Comités Regionales de Control, por lo que son éstos los que, a partir de la entrada en vigor de la Ley 62 , del 53, ejercen también el control sobre la actividad de los consorcios, y ello, con independencia de la materia, de competencia estatal o regional, para la que el consorcio fue constituido. Nada cabe subrayar en relación con los consorcios interprovinciales en lo que afecta al control gubernativo. La jurisdicción contable, inicialmente encomendada al Consejo de Prefectura de la provincia para los consorcios intermunicipales, y al Consejo de Prefectura de la provincia donde tuviera la sede el consorcio, cuando fueran interprovinciales, ha pasado a la Corte de Cuentas, como consecuencia de una sentencia de la Corte Constitucional, la número 55 de (17-5) 3 de junio de 1966.

(7) La Ley número 62 de 10 de febrero de 1953, en los preceptos referidos al control de los entes locales desarrolla el artículo 130 de la Constitución italiana que, en su apartado primero, dispone: Un órgano de las Regiones, constituido de acuerdo con una Ley de la República, ejercita, también en forma descentralizada, el control de legitimidad sobre los actos de las provincias, de los municipios y de otros entes locales». 
De acuerdo con el artículo 164, a través de la forma prevista para la constitución de estas tradicionales fórmulas asociativas, los consorcios intermunicipales o, incluso, en los que participe la provincia, pueden ser disueltos cuando concurran graves motivos de orden público o cuando solicitada la observancia de las obligaciones impuestas por la Ley, persista su violación; la decisión sobre su disolución corresponde a la autoridad, estatal o regional, que haya procedido a su aprobación. Si se trata de consorcios interprovinciales la decisión sobre su disolución corresponde al Ministro del Interior (art. 171 t. u.), si bien parece lógico que esta decisión haya pasado a la órbita de las Regiones en los casos en que hayan sido éstas las que han procedido a su aprobación. La extinción del consorcio, evidentemente, vendrá condicionada por la naturaleza, voluntaria o coactiva, de su constitución.

Esta normativa, que tan sumariamente ha sido embozada, ha dado a luz un tipo de consorcio de carácter monofuncional y sectorial, que busca su justificación en la realización de una obra o en la prestación de un servicio; pero, por otra parte, al que se le ha tildado de incapaz de adaptarse a la evolución y cambios propios de las entidades locales (8). Quizá esta nota -en ningún caso positiva - del instituto consorcial deba ser relacionada con el papel secundario que han ocupado los entes locales en el panorama administrativo italiano hasta la Constitución de 1947; en efecto, hasta la aprobación de este texto ni siquiera la doctrina ha visto en los entes locales el exponente de una colectividad, depositaria, por tanto, de la satisfacción de unos intereses generales; por el contrario, en la consideración dominante en aquellos momentos, los intereses locales son específicos, distintos de los referidos a la colectividad considerada en su conjunto (9). La constitución italiana de mediados de siglo, como en tantos otros aspectos, en éste imponen también un cambio de rumbo, y la autonomía local, constitucionalmente reconocida, favorece la aceptación de los entes locales como proyección de una colectividad, lo que suponen un marco más amplio de responsabilidades para estos entes.

Pues bien, a esta nueva perspectiva postconstitucional no se sustraen los consorcios, que de finalidades singulares y sectorializadas pasan en buena medida a desempeñar papeles programatorios (10); en esta línea se sitúan leyes como la número 991 de 1952, cuyo artículo 17 permitía a los consorcios de municipios redactar el plano general de mejora de la montaña, o el DPR número 987 de 1955.

(8) Cfr. Massimo VILlone: «L'associazionismo tra gli enti locali. Profili evolutivi», Quaderni Regionali, FORMEZ, núm. 39, p. 20.

(9) Cfr. M. VILLONE: «L'associazionismo tra gli enti locali...», cit., p. 21

(10) Cfr. M. VILlone: «L'associazionismo tra gli enti locali...», cit., pp. 21 y 22. 
relativo a la constitución de Consejos de Valle o Comunidades de Montaña, o el más reciente DPR número 1523 de 1967, para la constitución de consorcios en áreas o núcleos de desarrollo industrial, con claras responsabilidades programatorias; en fin, también cabría hablar de las Comunidades de Montaña previstas en la Ley número 1102 de 1971, pero a ellas, por su importancia, dedicaremos más adelante alguna atención.

En cualquier caso, el marco normativo proporcionado por los artículos 156 y ss. del t. u. ha permitido la formación de una variada gama de consorcios, variedad que se debe fundamentalmente a los sectores en los que han sido constituidos y a las dimensiones en que deben ejercer las competencias (11), si bien, la normativa aplicable en general es común a todos. Esta es la situación que encuentran las Regiones - multiplicidad de consorcios, monofuncionales, sectorializados y anárquicamente distribuidos en el territorio-; las cuales, a través de su propia legislación han incentivado la constitución de nuevos consorcios y otro tipo de asociaciones entre municipios (12), política regional que incluso es anterior a la aprobación de el DPR número 616 de 24 de julio de 1977 (13), que, como se verá más adelante, tienen una gran importancia en lo que a colaboración entre entes locales se refiere; de todas formas, por la razón que acaba de exponerse, podría afirmarse que, en relación con el tema aquí tratado, el DPR número 616 ha recibido y formalizado una práctica regional, es decir, la política de favor hacia las formas asociativas intermunicipales, cual podría deberse, o bien a la intención de dar

(11) Vid. L. VANDELLI: Le autonomie territoriali..., cit., p. 278

(12) Por incentivos financieros algún autor ha entendido la diferencia entre las aportaciones realizadas por la Región en favor de los municipios considerados individualmente, es decir, no asociados, para el desarrollo de funciones cedidas; evidentemente las aportaciones en favor de municipios se realizan en mejores condiciones a los entes dispuestos a realizar la gestión de forma supramunicipal; Vid., AURELIO BRUzzo: «nncentivi finanziari all'associazionismo tra comuni nella legislazione regionale», Quaderni Regionali, FORMEZ, núm. 39, p. 73.

(13) Los sectores que se han visto afectados por la tendencia regional a incentivar el asociacionismo municipal son muy diversos: servicios socio-sanitarios, formación profesional, urbanismo y planificación territorial, comercio, turismo y artesanía, agricultura..., en este sentido se puede tomar en consideración el consorcio socio-sanitario, promovido por algunas Regiones con anterioridad a 1977 para agrupar no sólo a municipios, sino también a provincias mediante incentivaciones financieras con objeto de que realizaran agrupadamente las funciones sanitarias y asistenciales de responsabilidad local: Ley del Lacio núm. 2 de 12 de enero de 1976, Piemonte, Ley número 41 de 9 de julio de 1976. En materia de formación profesional, por ejemplo, Ley toscana número 6 de 1976, que incentiva la Constitución de consorcios de ámbitos territoriales correspondientes a los distritos escolares entre provincias, municipios y Comunidades de Montaña para el ejercicio de las funciones delegadas en las Corporaciones locales. Con referencia a la gestión del territorio, por ejemplo, Ley Umbra, número 53 de 1974, que prescribe la formación de planes de conversación y desarrollo de los parques naturales que deben ser redactados por los municipios, singulares o asociados y Comunidades de Montaña; o la Ley número 40 de 1977, de la Región de Liguria, que atribuye la gestión de los parques a los entes territoriales interesados reunidos en consorcios. En general, puede seguirse esta tendencia en $A$. Bruzzo: Incentivi finanziari... cit., p. 77 y ss. 
acogida por parte del Estado a la voluntad mostrada por ciertas Regiones, o bien al deseo de dar entrada a éstas en la formulación de una nueva ordenación de los entes locales (14).

\section{Las comunidades de montaña}

Con precedentes en las normas del DPR número 987 de 1955 sobre constitución de Comunidades de Montaña o Consejos de Valle, la Ley estatal número 1102 de 1971 crea las nuevas Comunidades de Montaña (15), cuya naturaleza jurídica no es otra que la de una entidad local, tal como lo son los municipios y provincias (16). La norma en cuestión no agota el régimen jurídico aplicable a las Comunidades de Montaña, al renunciar el Estado a disciplinar en su totalidad este nuevo tipo de entidad local y remitir a las Regiones la formulación del complemento normativo exigido por la Ley estatal; de acuerdo con este reparto, se ha dicho que «la Ley número 1102 constituye un modelo basado en la compartición por el Estado y las Regiones del proceso de decisión relativo a la reordenación de los poderes locales en Italia» (17).

La remisión que a la legislación regional realiza la Ley estatal número 1102 supone, lógicamente, que la Comunidad de Montaña no obedezca a un régimen jurídico uniforme - con lo que quiebra la tradicional uniformidad de los entes locales-pudiendo cada Región definir un régimen propio respetando los dictados de la citada Ley. Las posibilidades que se ofrecen a las Regiones son variadas: a éstas corresponde la determinación del territorio de las Comunidades de Montaña, atendiendo a la homogeneidad de la zona a integrar y, según el artículo 3 en su apartado último, de acuerdo con los municipios interesados, previsión que exige conjugar el ejercicio de la potestad legislativa regional con la voluntad de los municipios a integrar (18); a ellas también corresponde, por remisión del artículo 4 la determinación de la estructura de la Comunidad de Montaña, que constará de un

(14) Vid. A. Bruzzo: Incentivi finanziari..., cit., p. 85.

(15) Entre las diferencias más relevantes, pese a su idéntica denominación, cabría destacar: la globalidad de intereses encomendados: desde su inicial configuración a los poderes planificatorios de las actuales Comunidades de Montaña, frente a los limitados fines actuables por los Consejos del valle; a esta importante diferencia hay que añadir el carácter facultativo de estos últimos que contrasta con la necesidad de las Comunidades de Montaña previstas por la Ley 1102 de 1971.

(16) Si alguna duda podía ofrecer la naturaleza jurídica de las Comunidades de Montaña, la Ley número 382 de 1975 al otorgar al Gobierno la potestad de dictar Decretos legislativos a fin de completar el régimen de las Regiones de carácter ordinario, ha previsto en su artículo 1.e la posibilidad de que el Gobierno delegue en las provincias, municipios y Comunidades de Montaña funciones administrativas, en el marco del artículo 117 de la Constitución, de interés exclusivamente local.

(17) Francesco D'Onofrio: aLe comunitá montane nel processo di riassetto dei poteri localio, Rivista Trimestrale di Diritto Pubblico, 4, 1976, p. 1584.

(18) Sobre esta cuestión, F. D'OnOfaro: Le comunitá montane..., cit., p. 1586. 
órgano de deliberación, en el que necesariamente tendrán representación las minorías, un órgano ejecutivo, que ha de estar inspirado en una visión unitaria de los intereses de los municipios partícipes (19). Estas Leyes también han de establecer los criterios a seguir para el reparto de los fondos, bien sean estatales o regionales, asi como la regulación de las relaciones entre la comunidad y otros entes cuya actividad incida en su territorio, previsión ésta que por vez primera supone que las Regiones puedan entrar a regular aspectos de los municipios y provincias en cuanto a su relación con las Comunidades de Montaña.

A nuestros efectos, particular importancia tiene señalar algunos hitos que marcan la evolución del marco competencial de estos entes. Concebidos en su inicio como entidades de planificación económicosocial y del urbanismo, pronto el legislador estatal, por medio de la trascendental Ley número 382 de 1975 (art. 1.e) autoriza al Gobierno la adopción de Decretos Legislativos dirigidos a atribuir a la provincia, municipios y Comunidades de Montaña, de acuerdo con el artículo 117 de la Constitución, funciones administrativas de interés local. La Ley que se acaba de citar, de cuya habilitación surgió el DPR número 616 de 1977 de que más tarde se hablará, es evidente que deja de concebir a las entidades de montaña como entes de exclusiva programación, proyectando sobre ellas la posibilidad de asumir nuevas funciones gestoras. Por su parte las Regiones, aunque encuentran habilitación expresa para delegar competencias de gestión en las Comunidades de Montaña, también por efecto de la Ley estatal número 382 del 75, lo cierto es que con mayor jerarquía el artículo 118 de la Constitución, en su último apartado, tiene previsto que las Regiones ejerciten normalmente sus funciones administrativas delegándolas en provincias, municipios y otros entes locales; entre estos últimos se situan las Comunidades de Montaña por lo que ningún obstáculo ha existido para que las Regiones, ya desde hace algunos años, vengan dictando leyes de delegación de sus propias funciones administrativas en las Comunidades de Montaña( 20).

(19) En ejecución del artículo 4 de la Ley número 1120 de 1971, la mayoría de las Regiones han previsto que el órgano ejecutivo de la Comunidad sea elegido por mayoría absoluta de los componentes del Consejo de la Comunidad; sin embaro algunas Regiones han dispuesto que en el órgano ejecutivo esté presente necesariamente uan representación de las minorías; esta última previsión ha sido objeto de atinadas críticas ya que puede.llevar al bloqueo sistemático de la actividad del ejecutivo y, por otra parte, obstaculiza la identificación de la responsabilidad política del órgano ejecutivo ante los ciudadanos, al dificultar el juego de la mayoría-oposición. Vid. en este sentido. Pietro Ciarlo: «Organizzazione sovracomunale e regioni», Quaderni Regionali, FORMEZ, número 39, p. 58.

(20) En este sentido, Leyes números 6 y 20, ambas de 1978, respectivamente de las Regiones de Liguria y Veneto, en materia de agricultura; la Ley número 38, también de 1978, de la Región del Piemonte, que atribuye a las Comunidades de Montaña competencias en caso de calamidades naturales; la Ley número 29 de 1978, de Umbría, permite a las Comunidades de Montaña asumir funciones del consorcio socio-sanitario. 
La propia Ley creadora de estas entidades locales prevé, artículo 6 , que los municipios que formen parte de la comunidad puedan delegar en ellas el ejercicio de algunas de sus propias funciones (21), fundamentalmente aquellas que no pueden ser realizadas eficazmente en el nivel municipal. En sentido inverso, este mismo precepto prevé la posibilidad de que las Comunidades de Montaña puedan delegar en otros entes locales la realización de sus específicas funciones en el ámbito de su territorio.

\section{La colaboración entre entes locales en el marco de la reforma sanitaria}

Por exigencias del artículo 32 de la Constitución, la República es responsable de la tutela de la salud como derecho fundamental del individuo, por ello, en la década de los años 60 los poderes públicos se proponen realizar una reforma de la sanidad de tal forma que el servicio llegue a todos los ciudadanos, rompiendo con ello una irrazonable prestación sanitaria, obediente muchas veces, sobre todo en cuanto a la ubicación de los centros, a motivos muy distantes de lo que exige un plan de radicación de los mismos mínimamente razonable (22). En estas circunstancias, y con la responsabilidad de hacer realidad un servicio sanitario para todo el territorio nacional, era necesario crear una organización adecuada, que, por imperativos constitucionales no debería pertenecer al Estado, toda vez que la asistencia sanitaria y hospitalaria forman parte de la responsabilidad directa estatal y local y, por otra parte, una decisión en sentido contrario se hubiera enfrentado con el generalizado proceso de transferencias desde el Estado hacia la periferia que vivía Italia en aquellos años. Por todo ello y por el patente deseo de asegurar la participación y el control del ciudadano, se busca erigir una organización sanitaria vinculada a los municipios; pero la responsabilización municipal de un servicio de este tipo choca en un secular problema: la variedad y multiplicidad de los municipios italianos que imposibilita una gestión adecuada, ante lo cual y ante la falta de una opción clara en favor del reagrupamiento forzoso, de, al menos, los pequeños municipios, el DRP número 616 y la Ley número 833, de los años 77 y 78 respectivamente, recurren a la atribución de la gestión sanitaria a los entes municipales, pero su ejercicio ha de ser

(21) Se ha señalado la incongruencia de que la Ley número 1102 de 1971 no haya previsto igual posibilidad para ser actuada por las provincias en favor de las Comunidades de Montaña, Vid. F. D'Onofrio: Le comunitá montane..., cit., p. 1591.

(22) El origen de muchos centros sanitarios, con frecuencia, se encuentra en fundaciones de beneficiencia creadas de forma altruista en siglos anteriores Vid. GIANFranco Mor.: «Le unitá sanitarie locali: un modello applicabile in altri settori?», Quaderni Regionali, FORMEZ, núm. 39, pp. 128 y 129.

REVISTA DE ESTUDIOS.-5 
analizado en ámbitos territoriales definidos por la Región, y cuando este ámbito corresponde a los términos de varios municipios, la gestión del servicio ha de realizarse de forma asociada.

El citado Decreto número 616, de 24 de julio de 1977, del que se ha hecho alguna referencia, proporciona como se verá nuevas vías a la colaboración y asociacionismo intermunicipal. No obstante, antes de entrar a analizar las cuestiones contenidas en el artículo 25, que es precisamente el que da a luz nuevas fórmulas colaborativas, al hilo de lo que se ha expuesto sobre las Comunidades de Montaña, parece oportuno tomar en consideración una importante previsión contenida en esta norma de reordenación de las competencias territoriales; me refiero al apartado cuarto de este artículo 25, en el que se dispone: "cuando los ámbitos territoriales coincidan con los de las Comunidades de Montaña, las funciones del presente artículo son asumidas por las Comunidades de Montaña mismas». Las funciones a que se refiere este apartado son las relativas a la organización y prestación de los servicios de asistencia y beneficiencia y socio-sanitarios; en definitiva, como se ha indicado anteriormente, las Comunidades de Montaña, concebidas en principio, fundamentalmente como entes de programación, con esta importante previsión asumen competencias de gestión en el sector socio-sanitario (23).

Es en relación a este sector donde el artículo 25, apartado segundo y tercero, de este Decreto abre nuevas formas de colaboración entre entes locales; en efecto, a las Leyes regionales corresponde, oídos los municipios interesados, la determinación de los ámbitos territoriales adecuados a la gestión de los servicios sociales y sanitarios, promoviendo formas de cooperación entre los entes locales y, si fuera necesario, promoviendo, de acuerdo con el último apartado de artículo 117 de la Constitución, formas obligatorias de asociación entre los mismos. Con una somera lectura del precepto aparece sin más el novum que aporta: al mandato que realiza a las Regiones para que determinen los espacios territoriales para la gestión de los servicios socio-sanitarios, sigue la habilitación que a éstas confiere para promover la cooperación entre entes locales

(23) No es el artículo 25 en su apartado cuarto el único precepto del DPR número 616 de 1977 que atribuye funciones gestoras a las Comunidades de Montaña; asi, el artículo 9 otorga a estas funciones de policía administrativa en las materias a ellas transferidas; también el artículo 83 reserva a las Comunidades de Montaña algunas responsabilidades en la Administración de los parques nacionales y reservas naturales. Aunque el sector socio-sanitario ha sido el que en mayor medida se ha visto afectado por la renovada proyección gestora de las Comunidades de Montaña, ciertamente, éste no ha sido el único, en este sentido cabe citar algunas leyes estatales posteriores al DPR número 616: la Ley número 650 de 1979, sobre contaminación de las aguas, que atribuye a las Comunidades de Montaña, entre otras, las competencias de control y gestión sobre vertidos en el suelo y en el subsuelo; la Ley 925 de 1980, que permite a las Regiones disolver los consorcios de cuenca y transferir a las Comunidades de Montaña sus funciones. 
territoriales; bien puede observarse que la expresión promover remite a un asociacionismo voluntario que no precisa de ninguna habilitación legal en favor de las Regiones, toda vez que la decisión la conservan las propias entidades locales; supone, sin embargo, una importante novedad y por ello precisa de una concreta habilitación, la atribución a las Regiones de la potestad para promover la obligatoria asociación de municipios (24), por lo que el legislador estatal ha tenido que conectar esta previsión con el artículo 117 de la Constitución, que permite al Estado trasladar competencias a las Regiones a través de leyes constitucionales, porque, en definitiva, con esta atribución, las Regiones quedan habilitadas para incidir en la estructura y organización de los entes locales, competencia que si no les es transferida no les es disponible.

Otra importante aportación renovadora del precepto que ahora nos ocupa está en la elasticidad, justamente destacada por la doctrina (25), con la que se conciben las fórmulas de cooperación interterritoriales, elasticidad que tienen diversas manifestaciones; en unos casos aquélla se materializa a través de simples acuerdos entre los entes locales, sin que den lugar a personificación alguna, en otros casos del acuerdo puede surgir una asociación individualizada como sujeto jurídico; de cualquier forma, la decisión corresponde adoptarla a las Regiones, cuya única vinculación está en la idoneidad del espacio territorial demarcado para la gestión de los servicios socio-sanitarios, decisión que dada la amplitud del término idoneidad, alcanza, en definitiva; a la elección de los entes territoriales cuyo concurso se necesita para dar vida a la forma de cooperación (26). Sin duda, no es oportuno descartar rotundamente las posibilidades que ofrecen los simples acuerdos entre entes locales a los efectos de dar cauce a una serie de intereses convergentes para la gestión de sus competencias, incluso más allá del sector sociosanitario, pero lo cierto es que tampoco en Italia ha pasado desapercibida para la doctrina la debilidad de estas formas cooperativas al margen del asociacionismo en sentido técnico, porque, en definitiva, su eficacia

(24) «Promover» formas «obligatorias» es manifiestamente contradictorio, en cuanto que una asociación obligatoria no es promovida, sino constituida a través de un acto de autoridad. Vid. M. VILLONE: L'associazionismo..., cit., p. 29.

(25) Vid. M. VILLONE: L'associazionismo..., cit., p. 30; L. VANDELLI: Le autonomie territoriali..., cit., p. 281

(26) Nótese que, con evidente incongruencia; el artículo 25 del DPR número 616 de 1977. posibilita a las Regiones, según se ha visto, la determinación de los ámbitos territoriales adecuados a la gestión de los servicios socio-sanitarios, además de la promoción y constitución obligatoria de fórmulas de cooperación entre entes locales territoriales, sin embargo, y ahi está la incongruencia, sólo exige que sean oídos los municipios interesados, cuando pueden formar parte de este tipo de formas de colaboración, por ejemplo, las provincias, los consorcios, las Comunidades de Montaña... 
depende de la voluntad de los sujetos intervinientes, sin que tampoco parezca aconsejable ni eficaz la sustitución del acuerdo voluntario, respetuoso con la autonomía de los entes intervinientes, por la intervención más o menos coactiva de otro sujeto, en el caso italiano la Región (27).

Otro de los temas que creo merece la pena subrayar de este artículo 25, es la toma de posición por parte del legislador, al menos así lo ha creído algún sector doctrinal, sobre un aspecto que parece capital a la hora de diseñar el marco normativo para la gestión de los servicios de responsabilidad local a través de la agrupación de entes de esta naturaleza: me refiero a la, defendida por algunos, superación de la tendencia a considerar la eficacia en la prestación del servicio en relación dependiente de la determinación del área territorial idónea para su gestión, para, a partir de esa individualización territorial, erigir la correspondiente asociación intermunicipal. Esta superación se manifiesta en la localización de ámbitos adecuados a la prestación de una duplicidad de servicios, los de carácter social y los sanitarios, a partir de lo cual ha de procederse a buscar la fórmula de colaboración más oportuna, pero sobre todo esta tendencia aparece con más evidencia en el ya citado apartado cuarto de este artículo 25 que, como se recordará, atribuye a las Comunidades de Montaña la gestión socio-sanitaria cuando los ámbitos territoriales determinados en cumplimiento de este precepto coincidan con los propios de las Comunidades de Montaña existentes, con lo cual, a estos entes locales territoriales se les asigna, además de sus peculiares funciones, las derivadas de la gestión de los servicios socio-sanitarios. Aunque el tema, como más adelante podrá comprobarse, no es pacífico en la doctrina, pues aboca ni más ni menos que en la disyuntiva monofuncionalidad-plurisectorialidad de las asociaciones intermunicipales, se ha señalado, decía, que esta nueva -y quizá parcial visión- perspectiva obedece a las dificultades para definir, desde la óptica de la eficacia de cada servicio, el marco territorial óptimo para su prestación, de ahí la asignación a un mismo área de varios servicios; a ello se ha añadido, ahora ya desde un punto de vista más socio-jurídico, que la plurisectorialidad de los entes intermedios responde al deseo de sobreponer a la prestación del servicio la colectividad, formada por los habitantes de varias entidades locales, destinataria de aquéllos, de tal forma que ésta aparece como la receptora de un equilibrado haz de servicios, de cuya prestación ha de responderse no individualmente, uno por uno, sino del conjunto (28). Quizá éste sea

(27) Cfr. M. Villone: L'associazionismo..., cit., pp. 34 y 35

(28) Cfr. M. Villone: L'associazionismo..., cit., pp. 27 y 28. 
un paso necesario en el camino hacia fórmulas comprometidas con la reducción del número de municipios en Italia.

Un año después de la aprobación del DPR número 616 de 1977, la Ley número 833 de 1978 da luz verde a la reforma sanitaria en Italia, y, por lo que ahora interesa, crea las unidades sanitarias locales, cuyo artículo 15 define como estructuras operativas de los municipios, individuales o asociados y de las Comunidades de Montaña; estructuras destinadas a actuar, al menos en principio, en el campo socio-sanitario, dentro del área territorial definido en sede regional. Aun siendo una simple estructura, por tanto, privada de personalidad jurídica (29), dispone de una organización interna propia, que inicialmente estaba compuesta por una asamblea general, un comité de gestión y un presidente (30), organización que con posterioridad ha sufrido alguna alteración por Ley número 4 de 15 de enero de 1986.

La creación de las unidades sanitarias locales con carácter general a lo largo de todo el territorio nacional ha traído de nuevo el debate a cerca de la aptitud de éstas para recibir el encargo de gestionar competencias en otros sectores. El tema ya fue apuntado más arriba y a lo dicho vamos a añadir ahora algunas otras consideraciones. Al margen de que sean o no idóneos para la prestación de otro tipó de servicios los espacios territoriales elegidos por las Regiones para gestionar los servicios sociosanitarios, aparece como un obstáculo jurídico difícilmente franqueable la dudosa constitucionalidad de las normas regionales que impusieran a los municipios la gestión de sus propias competencias a través de fórmulas asociativas; este tipo de imposiciones sólo pueden venir, en su caso, dispuestas por la legislación estatal, por ser el Estado el único competente para regular el régimen local; solamente las Regiones podrian actuar en el sentido expuesto mediante previa habilitación estatal, como así ha ocurrido con el DPR número 616 de 1977 (art. 25). Incluso, en delegación de sus propias competencias, la previsión regional obligando a constituir formas asociativas para su gestión podría dar lugar a invasión por

(29) Sobre este particular ha existido una importante controversia doctrinal, sin embargo ésta es la opinión dominante. Vid. L. VANDELLI: Le autonomie territoriali..., cit., p. 283.

(30) En lo que afecta a la estructura y funcionamiento de las unidades sanitarias locales, la Ley número 833 de 1978, su artículo 15, ha sido modificado por la Ley número 4 del 15 de enero de 1986; entre otras novedades que introduce, suprime la asamblea general, cuyas competencias serán gestionadas, según los casos, por el consejo municipal, la asamblea de la Comunidad de Montaña o la asociación intercomunal; además ha modificado algunos otros aspectos de las unidades sanitarias locales obligando a las Regiones a adecuar su propia normativa de desarrollo de la Ley de reforma sanitaria a los dictados de la Ley de 1986 . Sobre las modificaciones introducidas por esta Ley Vid. ANTONIO MARTINO: «L'attuazione della legge 15 gennaio 1986, n. 4 sul nuovo assetto organico delle UU.SS.LL.», Regione e goberno locale, núm. 3, 1987, p. 31 y ss 
parte de las Regiones de competencias estatales en materia local, por lo que solamente la incentivación aleja el peligro de inconstitucionalidad (31). Para terminar, tampoco ha sido ajena a la doctrina italiana la discutible legitimidad democrática de las organizaciones electivas de segundo grado a que se remiten los entes intermedios, siempre más alejados del control popular, por lo que se ha visto con alguna desconfianza la atribución de otros sectores, además del socio-sanitario, a las formas asociativas que mantienen a las unidades sanitarias locales (32) seguramente, entre otras, este tipo de consideraciones han favorecido la tendencia actual contraria a las asociaciones plurisectoriales, tal como ha destacado la doctrina más atenta (33).

\section{Otras fórmulas de composición de intereses interterritoriales}

Particular fortuna han tenido, fundamentalmente, durante la década de los años 70, los comprensorios, circunscripciones territoriales de muy variada extensión y competencias, tanto programatorias como de gestión, en que algunas Regiones han dividido su territorio con la finalidad de coordinar su administración con la municipal, animadas, además, en aquellos momentos, por el objetivo de superar la provincia como entidad local. En general, los compresorios se han incorporado a la estructura organizativa de las Regiones como órganos periféricos de éstas, aunque integrados por representantes de los entes locales (34). El paso del tiempo, sin embargo, según ampliamente reconoce la doctrina, ha agotado las posibilidades de los comprensorios; el inicio de la década de los años 80 está marcada por su creciente supresión y, paralelamente, por la renovada confianza en la provincia heredera en muchos casos de las competencias de aquéllos (35).

El artículo 129, apartado segundo de la Constitución italiana dispone: «Las circunscripciones provinciales pueden ser subdivididas en distritos (circondari) con funciones exclusivamente administrativas para una posterior descentralización»; con base en este precepto, estas circunscripciones han servido de marco territorial para la

(31) Algunas regiones (Toscana, Umbría) han apostado por la creación de entes intermedios de carácter plurifuncional, con competencias más allá del sector socio-sanitario (respectivamente Ley número 31 de 17 de agosto de 1979 y Ley número 65 de 19 de diciembre de 1979); la primera, sin embargo, por Ley número1 2 de 24 de marzo de 1986, ha dispuesto que las funciones administrativas regionales son delegadas o atribuidas a provincias, Comunidades de Montaña y municipios, y a partir de esta previsión (art. 2.3), los municipios voluntariamente podrán elegir entre ejecutar esas competencias individualmente o en forma asociada.

(32) Cfr. G. Mor: Le unitá sanitarie locali..., cit., p. 141 y ss.

(33) Vid. L. VANDELLI: Le autonomie territoriali..., cit., pp. 286 y 287.

(34) L. VANDELLI: Le autonomie territoriali..., cit., p. 284.

(35) Cfr. Andrea Pubusa: Annuario delle autonomie locali, 1983, voz compresori, pp. 96 y 97 
actuación de algún órgano regional, pero si ésta ha sido su formulación más simple, en otros casos, los circondari, servidos por representantes de los entes locales, han asumido funciones semejantes a las desempeñadas por la provincia, en realidad, por esta vía, las Regiones están dando vida, si bien de hecho, a nuevas provincias, colmando las aspiraciones de ciertos territorios a constituirse en provincia (36). Este proceso está siendo repetido con cierta reiteración, de tal forma que parafraseando el título de un conocido artículo de U. РототschNig: "Le regioni istituiscono i circondari, ma pensano ai comprensori», Le Regioni número 1, 1974, se ha llegado a afirmar que «si en el pasado las Regiones instituian los circondari pensando en los compresorios, hoy instituyen los circondari, pero pensando en las provincias» (37).

\section{A modo de recapirulación}

Aún consciente de los límites dentro de los que se mueve este trabajo, creo que con él se da una idea de las coordenadas en que ha venido moviéndose hasta la actualidad la cooperación entre entes locales. Si alguna conclusión se puede obtener de la lectura de las páginas que preceden, ésta es la indefinición y la falta de rumbo de que han adolecido las experiencias de colaboración intermunicipal en las últimas décadas; las causas son múltiples, sin embargo, no parece aventurado aislar la vetustez del marco legal en que viven las Corporaciones locales, marco ideado hace más de cincuenta años, cuanto Italia no disponía de la organización regional que hoy existe ni la Administración, en general, había asumido compromisos prestacionales tan altos como los adquiridos en el Estado social.

Estas circunstancias y la falta de la voluntad necesaria para reordenar el régimen local han conducido a la sucesión de fórmulas cooperativas en ciertos casos sobre principios contradictorios. Así, mientras el consorcio ha mantenido a lo largo del tiempo su presencia en la vida local, incluso llegando a sectores distintos de los que tradicionalmente han reclamado su constitución, otros institutos, como los comprensorios, han tenido su auge más bien fugaz, coincidiendo con la rehabilitación del ente provincial, o, las Comunidades de Montaña, que han experimentado una evolución quizá no demasiado bien calculada, o, las unidades sanitarias locales, en las que se ha reflejado el debate sobre la monofuncionalidad o plurifuncionalidad de los entes locales intermedios.

(36) Es destacable el caso de Rimini, circondario para el que la Región de Emilia-Romagna, además de las funciones programatorias asignadas a los comprensorios, ha atribuido todas las competencias delegadas a las provincias, como si de una más se tratara. Vid. A. Pubusa: Annuario..., cit., p. 97.

(37) A. Pubusa: Annuario..., cit., p. 97. 
Todo ello apunta a una insatisfactoria regulación, sometida a frecuentes parches al no ser posible una reforma integral del régimen local, y como respuesta a esta insuficiente regulación hay que entender la huida de los propios entes locales hacia fórmulas cooperativas ad extra, como la utilización de instrumentos jurídicoprivados (consorcios de Derecho privado, sociedades de responsabilidad limitada, por acciones, ...), o los simples acuerdos para fines específicos, que sólo vinculan a los entes signatarios en los términos de sus contenidos.

\section{LOS ENTES LOCALES INTERMEDIOS EN LOS INTENTOS DE REFORMA DEL REGIMEN LOCAL}

La antigüedad de las normas reguladoras del régimen local, frecuentemente ha sido responsabilizada de muchos de los males que achacan el funcionamiento de los entes locales; en estas circunstancias es explicable que muchos gobiernos, y los partidos políticos, en general, se hayan propuesto, sin éxito, aprobar esta asignatura a lo largo de distintas convocatorias, por utilizar la metáfora de J. Tornos (38). Con este objetivo han sido presentados numerosos proyectos, sin que hasta la fecha ninguno haya obtenido los resultados esperados por sus mentores. Con los límites impuestos a este trabajo, es decir, las fórmulas asociativas de cooperación intermunicipal, analizamos a continuación los aspectos más sobresalientes que ofrecen los distintos proyectos de reforma del régimen local italiano.

\section{El llamado Proyecto de Pavia y los sucesivos de finales de los años 70}

El influyente Proyecto de Pavía, surgido en 1976 de una investigación realizada en la Universidad de esta ciudad, como ya se ha hecho notar, discrepa de quiénes sitúan la fusión de municipios como presupuesto para abordar la reordenación del régimen local; por el contrario, mantienen que este proceso, es decir, la fusión o, en su caso, la incorporación intermunicipal, ha de constituir un proceso voluntario precedido de la experiencia proporcionada por el funcionamiento de fórmulas de colaboración entre los municipios, de ahí, que el alabado Proyecto de Pavía conceda una capital importancia a los instrumentos de colaboración intermunicipal.

Son cuatro las formas a las que, los responsables del Proyecto de Pavía, reconducen la colaboración entre entes locales: los simples

(38) Tornos MAS, J.: «La reforma de la Administración local en Italia», RAP. núm. 112, p. 359 . 
acuerdos entre municipios, no originan ninguna estructura organizativa nueva, con ellos se pretende principalmente regular la adquisición o utilización de bienes o equipos por varios municipios; la gestión común carente de personalidad jurídica distinta de la de los entes signatarios pero necesitada de una organización propia, constituida por miembros de los consejos municipales interesados, va dirigida al ejercicio conjunto de servicios o también a la utilización de bienes en común; los consorcios, verdaderos entes locales dotados de personalidad jurídica, a los que se concibe con carácter monofuncional, para obtener la colaboración intermunicipal cuando ésta no puede conseguirse, o no da los frutos deseados, a través de las fórmulas anteriores; $y$, por último, las uniones de municipios, también dotadas de personalidad jurídica, sus funciones son mucho más amplias que en los casos anteriores, disponiendo incluso de competencias residuales para ejercer aquellas funciones pertenecientes a los municipios integrantes no excluidas expresamente. Evidentemente, esta última de colaboración entre municipios va directamente dirigida a facilitar la fusión en un futuro (39).

A partir de los trabajos realizados en la Universidad de Pavía, los sucesivos proyectos de reforma del régimen local que se redactan en los años siguientes, toman como punto de partida la realidad municipal italiana existente y no se arriesgan a defender, en otros tiempos terapéutica, cirugía municipal (40); en esta línea se mueven los proyectos presentados durante las legislaturas VII y VIII, entre 1978 y $1981(41)$.

No parece que el análisis detallado de estos proyectos tenga ahora mayor interés; sí es posible generalizar que los redactores de éstos han tenido muy presente los trabajos elaborados en Pavía, aceptando el cuadro institucional propiciado y a partir de él formular distintas soluciones para los instrumentos de colaboración intermunicipal. Así, todos los proyectos coinciden en dotar de gran flexibilidad los acuerdos a que pueden llegar los municipios con objeto de utilizar bienes en común, realizar trabajos también de común interés, o incluso la gestión de un servicio por parte de un municipio en beneficio de varios; en ningún caso se superpone la creación de una nueva persona jurídica, ni siquiera de un órgano de gestión; en realidad, la posición de las partes obedece, más que a los contenidos

(39) Más ampliamente que en la presente exposición, puede verse: L. VANDELLI: / modelli associativi nei progetti di riforma..., cit., pp. 175 y 176.

(40) Cfr. L. VANDELLI: I modelli associativi nei progatti di riforma..., cit., p. 177.

(41) Sobre todos ellos, presentados por el Gobierno, Senado y Partidos políticos, puede consultarse un amplio estudio de sus contenidos en L. VANDELLI: «Le autonomie locali verso la riformax. Progetti e documenti. Maggioli; Rimini, 1981. 
de la norma (los proyectos respectivos), a las estipulaciones aceptadas por ellas.

La llamada gestión común, también sin personificación, estaba prevista en algunos proyectos. La simple constitución de órganos intermunicipales debería atender a finalidades diversas: prestación conjunta de servicios, elaboración de planes de ordenación territorial...; también dotados de gran flexibilidad, todos los proyectos remiten al reglamento posterior que han de aprobar los consejos municipales, la estructura y funcionamiento de los órganos gestores.

En relación con las asociaciones intermunicipales personificadas propiamente dichas, la variedad entre los distintos proyectos es notable; así, en unos casos se prevé la constitución obligatoria, en otros es facultativa para los municipios, siendo a veces dicha constitución de responsabilidad estatal y otras de responsabilidad regional. Si se atiende a la organización de los entes resultantes, las diferencias entre los proyectos son también amplias; aún respetando la formulación tradicional que reduce la organización a una asamblea, un comité ejecutivo y un presidente, las combinaciones son múltiples a la hora de determinar la formación o elección de cada uno de estos órganos y sus competencias, así como el papel a desempeñar por el Estado y las Regiones en la regulación de los mismos. También las responsabilidades atribuidas a los consorcios varían: desde el modelo tradicional de consorcio monofuncional, en unos casos, se llega, en otros, hasta el más renovado, en aquellos momentos, modelo plurifuncional, tendencia esta última que seguramente a finales de los años 70 tenía como objetivo crear fórmulas consorciales que abocaran en la fusión de municipios.

- Por último, también las uniones encontraban en los distintos proyectos importantes matices; en unos casos la unión habría de disponer únicamente de competencias concretas, incluso a veces estaba prevista con carácter monofuncional; contrariamente, en otros, la unión era concebida con competencias cuasitotales en relación con los municipios integrantes. En general, como la finalidad de estas uniones era preparar la fusión, la mayoría de los proyectos entendieron que pasado un tiempo prudencial de funcionamiento de la unión, por Ley regional y oídos los municipios interesados se habría de proceder a formalizar la fusión.

2. Proyecto de la UK Legislarura, presentado el Th de abril de 1985

Lo primero que se aprecia tras la lectura de los seis artículos (1520) que este proyecto dedica a las formas asociativas y de cooperación intermunicipal, es el abandono de la variada tipología adoptada por 
los proyectos anteriores; ahora parece no haberse tomado en cuenta las soluciones aportadas por el grupo de Pavía y los proyectos posteriores. En efecto, en el intento de reforma del régimen local italiano del 85 son dos las formas a que se reconduce la cooperación intermunicipal: los simples acuerdos, con la finalidad de coordinar funciones y servicios determinados, para los que no se prevé ningún régimen jurídico específico al margen del propio acuerdo, y las asociaciones para la gestión conjunta de uno o más servicios.

Además de la escueta regulación que contiene este texto, la cuestión que seguramente llame más la atención es la sensible marginación que sufren las Regiones, quebrando con ello, al menos desde la perspectiva del derecho proyectado, el creciente protagonismo que venían alcanzando en relación con las entidades locales. Esta nueva tendencia es palpable en todo el articulado, y así ha sido evidenciado en nuestra propia doctrina (42); por lo que se refiere a nuestro tema, la intención de desapoderamiento regional es palpable toda vez que el artículo 19 disponía que a éstas corresponde promover y favorecer las formas asociativas y de cooperación entre los entes locales y prestar asistencia técnica y financiera, mientras que al Estado, y sólo a éste (art. 20) le está permitido mediante Ley y en caso de relevantes intereses públicos así lo demanden, la constitución de asociaciones intermunicipales obligatorias. En definitiva, a través de las sencillas fórmulas antes señaladas, el redactor del proyecto pone la colaboración intermunicipal a disposición de la libre decisión de los entes locales, movido, quizá, por el deseo de salvaguardar la autonomía municipal de la ingerencia regional, queriendo consumar de esta forma el peligro sentido en algunos sectores de que los entes locales queden convertidos en instituciones dirigidas por las Regiones. A la opción por la que se inclina ahora el redactor del proyecto, seguramente no sea ajeno el debate que en aquel momento se mantienen en altas instancias de la nación en torno a las relaciones centro-periferia, en el que paradójicamente se tiende a reafirmar el papel de las Regiones en orden a la integración de los diversos niveles territoriales; a decir verdad, el texto del proyecto parece decididamente influido por la tesis de Riccardo Triglia (Presidente de la ANCl, Asociación Nacional de Municipios Italianos), partidaria de defender la autonomía local frente a injerencias regionales, por una parte, y el asociacionismo intermunicipal voluntario, por otra (43).

Fácilmente se entenderá que el no disimulado olvido de las Regiones en lo que a la posible constitución de asociaciones

(42) TORnos MAS: La reforma de la Administración local..., cit., p. 575.

(43) Vid. sobre el tema, Marco CAMmELl: aLe forme associative tra i comunis, Regioni $e$ goberno locale, núm. 1, 1986, p. 60 y ss. 
intermunicipales se refiere, no pasó desapercibido para la doctrina, siendo objeto de duras críticas por parte de autores de relieve (44); en este sentido se resaltó la intrínseca contradicción que suponía el artículo 19 del proyecto, al atribuir a las Regiones la promoción y favorecimiento de las formas asociativas y de cooperación intermunicipal de acuerdo con la programación regional, y la absoluta dependencia, en cuanto a la constitución de las asociaciones, de la voluntad de los propios municipios. Las críticas a este proyecto se extendieron a lo que de retroceso implicaba esta solución si se la compara con la aplicación que en algunos casos se venía haciendo (45) del t. u. de 1934, que permitía a las Regiones imponer, en algunos casos, la constitución coactiva de consorcios, posibilidad ahora negada por el artículo $20 \mathrm{del}$ proyectado texto de la autonomía local, negación, que, se afirmaba, no encuentra apoyo en la Constitución, ya que los artículos 117 y 133 otorgan a las Regiones responsabilidad en la organización de la Administración local.

Como sagazmente se ha visto (46), el texto del proyecto pretende dar cabida a tres posiciones diferentes y en buena medida contradictorias: en primer lugar, la de quienes conciben las asociaciones intermunicipales como un simple instrumento para conseguir el máximo de responsabilidades para los municipios, evitando, a través de la pantalla de la asociación, la tradicional objeción de inoperancia sobre todo de los pequeños municipios; la de quienes pretenden reforzar las asociaciones intermedias con la finalidad de vaciar $y$ marginar a la provincia, en segundo lugar; y por último, la de quienes ven en estas asociaciones competidoras de los municipios individualmente considerados. Es evidente que una reforma navegando sobre posiciones a veces tan contradictorias, quizá pueda dar satisfacción a sus valedores, pero será una reforma enormemente lastrada y sin objetivos, como el propio Рототschnig anuncia en su trabajo.

\section{La colaboración intermunicipal en los textos propuestos en la actual (X) Legislatura}

Una vez más, los políticos italianos se han comprometido con la reforma del régimen local. En el último año y hasta la fecha han sido tres las propuestas de Ley (47), a las que hay que añadir el proyecto

(44) Vid. Umberto Pototschnig: aLe forme associative tra i comuni: una riforma senza objettivi», Le Regioni, 5, 1985, pp. 682 y 683.

(45) Vid. supra. nota núm. 5.

(46) U. Pototschnig: Le forme associative..., cit., pp. 684 y 685.

(47) La Democracia Cristiana presentó una propuesta el 4 de febrero de 198̄8, pub̄icađa por la Cámara de los Diputados con el número 2295; el Partido Comunista hizo lo propio el 4 de julio de 1988, número 2952; y el Partido Republicano, el 13 de diciembre de 1988, número 3441. 
de Ley realizado por el Gobierno (48). En general, y ahora también atendiendo al tema que ocupa este trabajo, se puede decir que no existen marcadas diferencias entre los contenidos de los cuatro textos; por el contrario, aún apareciendo importantes matices que les diferencian, se observa que todos los responsables de los distintos proyectos han tenido bien presentes los trabajos realizados en Pavía hace más de diez años.

Antes de detenernos en alguno de los aspectos más significativos de las figuras en que se materializa la colaboración entre entes locales, parece oportuno destacar una característica que con mayor o menor intensidad, es común a los cuatro textos, me refiero al papel llamado a desempeñar por las Regiones en la configuración de los distintos mecanismos colaborativos, papel en la actualidad no muy diverso del asignado y criticado en el proyecto de 1985 . En efecto, en todos ellos parece estar presente la idea de respeto a la voluntad de los municipios como expresión de su autonomía y ello a costa de reducir la intervención coactiva ya no sólo de las Regiones, sino también del Estado para imponer la creación de mecanismos de colaboración entre aquéllos. En algunos casos (proyecto gubernativo y propuestas de los partidos Comunista y Demócrata-cristiano), se prevé que tanto el Estado como las Regiones, en materias de su competencia, puedan disponer fórmulas de convención obligatoria entre municipios; además de esta intervención, el texto comunista pone a disposición de las Regiones la promoción de los acuerdos de programación con el fin de coordinar la acción integrada de municipios, provincias, región, Administración estatal y otros sujetos públicos; al Estado reserva, en fin, el texto demócrata-cristiano, en caso de que relevantes intereses públicos así lo exijan, la constitución obligatoria de consorcios u otras asociaciones, pudiendo solicitar incluso la actuación regional por medio de sus propias leyes. Mayores novedades en relación con los textos presentados contienen el presentado por el partido Republicano; en su artículo 12 dispone que por Ley original, oídos los municipios interesados, se individualizan los ámbitos territoriales en los que el ejercicio de las funciones municipales deben realizarse de forma asociada, de acuerdo con lo que dispongan las leyes estatales o regionales (art. 15), siendo éstos los marcos territoriales en los que los municipios pueden constituir la correspondiente asociación; pero además, sólo es posible crear una asociación por cada espacio territorial delimitado en sede regional (art. 12.2, in fine ), previsión esta última de notable importancia si se piensa que, al poder constituirse solamente una asociación por cada espacio territorial individualizado, parece que este texto apuesta por

(48) El proyecto gubernativo es de fecha 28 de junio de 1988, número 2924. 
la polifuncionalidad de las asociaciones $y$, lo que creo igualmente importante, por contribuir, además de a una eficaz gestión, a crear una conciencia de unidad entre los habitantes de los municipios asociados, al circunscribir todas las relaciones de colaboración intermunicipal a un territorio previamente definido. De consolidarse una previsión de este tipo, quizá se haya dado un paso adelante importante en el camino hacia la reducción del número de municipios en Italia.

Por lo demás, como ya se ha señalado, los instrumentos previstos en los textos de que ahora nos ocupamos, siguen, en general, las líneas marcadas en Pavía. Todos ellos, sin excepción, incluyen entre las formas de cooperación los simples acuerdos entre municipios o, en algunos casos, provincias u otras asociaciones intermunicipales, con el fin de coordinar funciones o servicios, adquirir bienes o realizar obras de interés común..., en general, el acuerdo o convención adoptados por los respectivos consejos de las entidades participantes deben establecer los fines, la duración, las relaciones financieras y obligaciones recíprocas de los entes intervinientes; en definitiva, dicho acuerdo, contiene la disciplina jurídica aplicable al objeto del mismo.

Unicamente la propuesta por el partido Comunista prevé la posibilidad de estabecer Administraciones conjuntas entre municipios con la finalidad de preparar y adoptar unitariamente planes territoriales, utilización de órganos o bienes en común, incluso, gestión de servicios, en cuyo caso, el reglamento adoptado por los municipios para disciplinar la Administración conjunta puede dotar de cierta autonomía dicha gestión. No aparece entidad distinta a los municipios intervinientes; las decisiones del órgano que realiza las funciones comunes se consideran adoptadas colectivamente por todos los municipios que han convenido la Administración conjunta (art. 23.3, in fine).

Los consorcios, figuras tradicionales del Derecho local italiano, sólo aparecen en el texto propuesto por la Democracia Cristiana (art. 37); se definen como agrupaciones de entes locales personificadas, en las que además del municipio y provincia pueden participar otros entes públicos, constituidas para proveer a la prestación de determinados servicios y obras de interés común y reguladas por la Ley y su propio estatuto. Tanto el texto preparado por el Gobierno, como los presentados por los partidos Republicano y Demócrata-cristiano introducen las asociaciones, en unos casos intermunicipales y en otros se admite la participación de la provincia (Partido Demócratacristiano); las proyectadas asociaciones tienen por objeto la gestión conjunta de uno o más servicios, si bien el texto republicano, de forma mucho más amplia, permite a los municipios gestionar sus 
competencias de forma asociada. Aunque los propios textos recogen algunas reglas sobre estas asociaciones (órganos, aplicación de ciertas normas referidas a la organización y funcionamiento de municipios y provincias...), la remisión al reglamento de cada asociación es inevitable; en él se contendrá la actividad o servicios a gestionar conjuntamente, denominación y sede de la asocicación, relaciones financieras, representatividad y funcionamiento de sus órganos.

Bastantes analogías tienen todas las regulaciones dispuestas en los textos sobre las uniones de municipios, concebidas siempre, como lo fueron en Pavía, como entidades creadas por varios municipios (de reducido número de habitantes), en función de su posterior fusión, para la gestión de una pluralidad de funciones o servicios. En general, se prevé una organización para el nuevo ente formada por un consejo, una junta ejecutiva y un presidente; siendo también previsión compartida la transformación de la unión en un único municipio o, en su caso, la disolución de ésta cuando no ha abocado en plazo determinado en la mencionada fusión. Aunque la constitución de la unión es voluntaria para los municipios representados por los correspondientes consejos, en algún caso la regla está matizada, como lo prueba la propuesta republicana, donde los consejos sólo pueden. dar su consentimiento para la formación de la unión después de consultar a la población interesada, o el texto comunista, que permite a las Regiones subsidiariamente tomar la iniciativa y disponer la constitución de la unión después de consultar a la población interesada mediante referéndum.

Las Comunidades de Montaña, sin duda, aparecen reforzadas en las proyectadas reformas del régimen local. Su constitución se hace depender de la decisión regional, a veces manifestada mediante Ley, sobre la base de los criterios que proporcionan los propios textos o (en el caso de la propuesta comunista) sobre los criterios determinados por las propias leyes regionales. El fortalecimiento de estas entidades es apreciable por el cúmulo de responsabilidades que es posible atribuirles, bien a través de las normas de la Comunidad Económica Europea, la Ley estatal o regional, o como consecuencia de las competencias delegadas por municipios y provincias. En definitiva, las Comunidades de Montaña se conciben como entes de desarrollo de la zona, aptos para gestionar competencias atribuidas directamente por las propias normas o delegadas por otros entes, sin descartar su expresada aptitud para servir a una posterior fusión de todos o parte de los municipios integrantes.

Para terminar, por lo que de fórmula de cooperación tiene, es oportuno hacer referencia a la coincidencia que presentan todos los 
textos sobre la constitución de áreas metropolitanas en aquellas ciudades y sus entornos que superen un número (variable según los textos) de habitantes. De esta forma, si algún día se realiza la reforma del régimen local en Italia, parece seguro que allí donde se constituyan estas áreas (Roma, Milán, Nápoles, Turín, Génova, ...) desparecerán las provincias correspondientes, y sus competencias serán gestionadas por éstas, que recibirán además otro tipo de responsabilidades (en algunos textos citadas de forma específica, en otros definidas genéricamente en atención a ciertos criterios: funciones atribuidas a los municipios, pero de carácter supramunicipal, razones de economía y eficacia que aconsejen la gestión conjunta...). Si la reforma se materializa, la creación de áreas metropolitanas obligará a modificar las circunscripciones de las provincias limítrofes, dado que el territorio sobre el que ha de asentarse el área no tiene por qué coincidir con la antigua provincia. 
REALA-1989, núm. 241. QUINTANA LOPEZ, TOMAS. LOS ENTES LOCALES COMPLEJOS Y OTRAS...

II. CRONICAS

REALA-1989, núm. 241. QUINTANA LOPEZ, TOMAS. LOS ENTES LOCALES COMPLEJOS Y OTRAS... 
REALA-1989, núm. 241. QUINTANA LOPEZ, TOMAS. LOS ENTES LOCALES COMPLEJOS Y OTRAS...

REALA-1989, núm. 241. QUINTANA LOPEZ, TOMAS. LOS ENTES LOCALES COMPLEJOS Y OTRAS... 